\title{
Exploring the consequences of human
}

\section{multitasking in industrial automation projects: a tool to mitigate impacts - Part II}

DOI 10.1515/otmcj-2016-0031

Received September 02, 2017; accepted December 16, 2017

Abstract: Each industrial automation project includes tasks that strongly depend on human factors, many of which may belong to the critical path or chain of the project. Multitasking significantly affects human productivity. The reduction in productivity has a direct result of delaying the primary task, which may cause an overall delay to the project with cost and time overruns. A project should be seen with respect to a global environment, such as that of a company, where resources are shared among its portfolio of projects. Although multitasking might have negative results, it is something that cannot be eliminated but can be mitigated by project managers.

This article presents the effects of multitasking on human productivity, especially when the tasks are complex, like programmable logic controller (PLC)/supervisory control and data acquisition (SCADA) software development. Using the analytical hierarchy process (AHP) method, a simple tool is created to be used by project managers, in order to assist them in decision-making. Criteria that influence these decisions are referenced, and their priority vectors are proposed. In addition, some real examples are given.

Project managers face a complex situation when they are asked to decide on the allocation of resources and priorities among different projects. Parameters that are difficult to predict in real situations may have a significant role in the decision-making process.

There are a lot of published works based on AHP applications in different fields, but there is a gap in the field of industrial automation projects and the related project

\footnotetext{
*Corresponding author: Kleopatra Petroutsatou, Laboratory of Planning and Project Management, Department of Civil Engineering, School of Engineering, Aristotle University of Thessaloniki, University Campus, 54124 Thessaloniki, Greece, Tel.: +30 6937041338; +302106817588, E-mail: kpetrout@civil.auth.gr
}

Anestis Sifiniadis, Hellenic Open University, Parodos Aristotelous 18, 26 335, Patra, Greece, E-mail: std097285@ac.eap.gr manager's decision-making. This study focuses on these decision-making processes that determine which tasks should be paused or not for a better allocation of resources, taking into account the global environment of a technical company. The tool can be implemented with changing criteria and priority vectors to adapt to different types of projects. Future research could identify additional criteria and subcriteria with different priority vectors, depending on different project specifications.

This article is the extended version (Part II) of CCC 2017 Procedia Engineering paper.

Keywords: multitasking, task switching, industrial automation projects, project performance, project manager's decision-making, AHP, project management tool

\section{Introduction}

Nowadays, the practice of multitasking is considered by many as a title of honor. Many studies have largely investigated the multitasking effects on human productivity, and conclusions are mostly negative (Adler and Benbunan-Fich 2012; Buser and Peter 2012). One of the areas directly affected by the impact of multitasking on human productivity is the software development area (Czerwinski et al. 2004; Gonzalez et al. 2005). An important part of industrial automation projects is related to software development, so multitasking is a key factor that can decisively impact the duration and cost of these projects.

Given that the daily stimuli in human beings are many, multitasking is very difficult to be avoided. The aims of this study are not only to minimize the multitasking to mitigate the impacts on the duration and cost of 
projects but also to serve the broader needs of a portfolio of projects within a technical company.

The decisions required to obtain from the project manager are often very difficult and influence greatly the performance of the project. The project manager is often called upon to decide whether or not to interrupt the critical operations of a project, in order to accommodate other requirements of the company. This article focuses on decision-making by project managers using the theory of multiple criteria decision-making (MCDM) and specifically the analytical hierarchy process (AHP) method. About 150 works have been published based on AHP, including applications in different fields such as planning, selecting a best alternative, resource allocation, resolving conflict and optimization (Vaidya and Kumar 2006).

Through the AHP method, a simple and user friendly tool is developed that can be useful in taking crucial decisions during an industrial automation project. Criteria that influence these decisions are referenced, and their priority vectors are given, in accordance with relevant experience in managing such projects. Finally, some real examples are given.

Future research could identify additional criteria with different priority vectors depending on the project specifications.

\section{Multitasking}

The term multitasking first appeared in 1965 in the IBM publication, which described the potential of the IBM System/360 (Witt and Lambert, 1965). In computer science, multitasking is a concept of performing multiple tasks over a certain period of time by executing them concurrently. The first CPU processors manufactured with one core, which was responsible for all of the software processing and its interface with the hardware. In fact, the core of the CPU processor cannot perform more than one task simultaneously but alternates the task execution. The speed with which the execution of the works is alternated is so fast that it gives the impression that the work is carried out simultaneously.

The multitasking cost of the CPU is the extra time required for saving and restoring the state of intermittent operations. This cost is called "context switching cost" and varies depending on the workload at different accesses to the memory and different architectures (Li et al. 2007).

\subsection{Human multitasking}

The concept of human multitasking began with the development of computer science. Human multitasking is the practice of performing many tasks in parallel by people, as do the CPU processors. Some examples of human multitasking are driving and simultaneously speaking on the mobile phone, answering an e-mail during a meeting and reading a magazine during cooking. According to Kenyon and Lyons (2007), human multitasking is the ability of execution or a combination of two or more tasks simultaneously or in parallel.

Nowadays there is a myth, especially in the business world, which says that human multitasking increases the productivity and effectiveness of people. In addition, technology Colossus is trying to propagate the world the ideal image of the superman who deals with many things simultaneously and effectively (smart phones applications, SMS, social media, online news, Internet research, etc.).

Everyone in daily life executes two or more parallel operations to gain some time. Unfortunately, it is impossible to focus simultaneously on all jobs. It has been scientifically proven that only $2.5 \%$ of people can do effective multitasking (Watson and Strayer 2010). A vast majority of people cannot respond to that. In fact, when a man thinks that he is multitasking, what actually he does is he successively switches the execution of two or more operations. Obviously, the cost in time is greater than the corresponding time cost of the CPU core.

\subsection{Impacts of human multitasking}

The scientific community has extensively dealt with human multitasking and its impacts on human performance. Specifically, multitasking reduces human productivity (Adler and Benbunan-Fich 2012; Buser and Peter 2012). According to the American Psychology Association (APA), the alternations between tasks may reduce productivity up to $40 \%$, and the more complex the task, the greater the impact on productivity (www.apa.org/research/action/ multitask.aspx). In addition, there are more errors after an interruption of a task (Monk et al. 2008).

Additionally, multitasking increases stress (Bailey et al. 2001) and causes fatigue and brain damage (Loh and Kanai 2014). A study with remarkable results showed that people who frequently multitask are worse at this than those people who do rarely (Ophir et al. 2009; Sanbonmatsu et al. 2013). 


\subsection{Why humans are multitasking}

Though multitasking has significant adverse effects on human beings and their work, it is observed that it is used because they either choose this way of work or are forced to do it.

There is a belief among employers that a good employee can perform multitasking effectively. Thus, some employees choose to perform several tasks in parallel, to indicate that they are busy. This makes them feel irreplaceable, better assessed and win the favor of their employer.

As mentioned, only $2.5 \%$ of people are able to perform effective multitasking (Watson and Strayer 2010). However, there are a large percentage of people who believe that they belong to that $2.5 \%$ of people. This illusion makes them believe that they are supermen, and they feel very proud of themselves. Especially, when some rare times multitasking works well, this strengthens their belief even more.

It has also been proved that several times the work undertaken by someone might cause a disappointment, which is a powerful incentive to make him or her go to switching of tasks (Hardy and Gillan 2012).

Although in the recent decades technological progress has greatly facilitated people's work, the easy Internet access for research, information and entertainment and the extensive use of smart phones (mail, SMS, social media) are important causes of interruption of work.

\section{Industrial automation projects}

One of the main areas in which automation is widely applied is the industry. In recent decades, technological progress has helped to increase industrial automation applications and reduce human intervention in industrial processes. The main advantages of the industrial automation applications are productivity growth, plant reliability, improvement in the quality of the final product, increase in worker safety and reduction in production cost.

Nowadays, the main part of an industrial automation system is usually based on programmable logic controllers (PLCs). PLCs are computer-based devices that are capable of controlling several types of industrial equipment and entire automated systems. The main feature of them is that they are very reliable and efficient in applications involving sequential control and synchronization of industrial processes (Alphonsus and Abdullah 2016).

If an industrial automation system is considered as a pyramid then the top is the supervisory control and data acquisition system (SCADA). Always, an SCADA system consists of subsystems such as human-machine interface (HMI), data gathering and alarm and event handling (Novak et al. 2014). SCADA systems provide interaction between the field devices and human operators.

Very often, PLCs have to control very critical industrial processes. In addition, the SCADA system must be user friendly in order to convey the necessary information to the operator. Both PLC hardware and SCADA system have to be programmed with appropriate software tools. The PLC/SCADA software development is the hardest part of the implementation of an industrial automation project. In addition, at the end of PLC/SCADA software development, there is the simulation phase, which is very critical because it tests the automation program simulating the actual process circumstances to identify and detect any software errors and correct them (debugging).

In organizations that rely on multi-project environments, resources are shared across a number of projects. An environment of many projects typically generates many priorities for project resources and managers alike (Patrick 1999). When several automation projects are executed in parallel, it is inevitable that resources are shared by more than one project. Also, the same resources are used in processes in addition to ongoing projects. Software development is a process that requires intense concentration, and these process interruptions reduce a developer's efficiency and can cause project delays (Solingen et al. 1998).

\section{Multiple-criteria decision-making}

MCDM refers to making decisions in the presence of multiple, usually conflicting, criteria (Xu and Yang 2001). In these cases, there is not a unique right decision. Through the MCDM, there is a ranking of all the alternatives and the decision is the best-ranked alternative from the decision maker, based on multiple criteria.

MCDM can be defined as the study of methods and procedures by which concerns about multiple conflicting criteria can be formally incorporated into the management planning process (www.mcdmsociety.org/content/mission-society).

\subsection{Analytical hierarchy process}

One of the major and most used MDCM methods is the AHP. The AHP was developed by Saaty (1980) and is used in most of the applications related to MCDM. AHP 
is an MCDM method that helps decision-makers to face a complex problem with multiple conflicting and subjective criteria (Ishizaka and Labib 2011).

To make a decision in an organized way to generate priorities, we need to decompose the decision into the following steps (Saaty 2008):

- Define the problem and determine the kind of knowledge sought.

- Structure the decision hierarchy from the top with the goal of the decision and then the objectives from a broad perspective, through the intermediate levels (criteria on which subsequent elements depend) to the lowest level (which usually is a set of the alternatives).

- Construct a set of pairwise comparison matrices.

- Use the priorities obtained from the comparisons to weigh the priorities in the level immediately below. Do this for every element. Then, for each element in the level below, add its weighed values and obtain its overall or global priority. Continue this process of weighing and adding until the final priorities of the alternatives in the bottom-most level are obtained.

\section{Project management tool}

About 150 works have been published based on AHP, including applications in different fields such as planning, selecting a best alternative, resource allocation, resolving conflict and optimization (Vaidya and Kumar 2006). In this study, we focus on the project manager's decision about pausing tasks of a current project, using the AHP method.

As mentioned, primary tasks of an industrial automation project are PLC/SCADA software development and the simulation of the whole project. Secondary task is considered as an urgent technical support, a bid preparation, a meeting, a task of another project or a task related to the internal operation of the technical company. Short distractions, such as a telephone call and a brief discussion, although affecting human productivity, are not taken into account in this study, considering that their impacts are smaller than those listed before.

Within a technical company, project managers are always faced with difficult decisions when task switching is required. In Greece, a few technical companies are involved in industrial automation projects. Based on the opinion of four senior project managers of automation projects (a significant percentage given that the companies specializing in automation projects are very few in Greece) with many years of experience, the following main criteria were identified for the decision-making process:

- Task criticality: the criticality of the main and secondary tasks is compared. For the main task, it is checked whether the task interruption affects the overall progress of the project (critical path), the projects risks, the project costs, and the customer dissatisfaction. For the secondary task, it is checked whether it is critical to another company's project, it is an urgent support to a specific customer and will cause financial cost, it is a task that causes financial cost to the company or it is a task that influences company's reputation.

- Task complexity: the complexity of the primary task is checked. The more complex the primary task, the greater the impact on restoring duration.

- Task duration: the total duration of the primary and secondary tasks is compared. The smaller the secondary task in relation to the primary task, the more acceptable the interruption of the primary task.

- Personnel appropriateness: check the appropriateness of the specific personnel to execute the primary and the secondary tasks.

The criticality criterion is the most important factor to be taken into account. In addition, the rank of complexity criterion is high. The duration and appropriateness criteria are less important than the first two criteria.

Using the fundamental scale of numbers that indicates how many times more important or dominant one element is over another element and making the pairwise comparison for the four criteria (Saaty 2008), the pairwise comparison matrix is made, as shown in Table 1.

Tab. 1: Pairwise comparison matrix of the 4 criteria.

\begin{tabular}{|c|c|c|c|c|c|}
\hline & Criticality & Complexity & Duration & Appropriateness & Priorities \\
\hline Criticality & 1 & 2 & 4 & 4 & 0.485 \\
\hline Complexity & $1 / 2$ & 1 & 3 & 3 & 0.297 \\
\hline Duration & $1 / 4$ & $1 / 3$ & 1 & 1 & 0.109 \\
\hline \multirow[t]{2}{*}{ Appropriateness } & $1 / 4$ & $1 / 3$ & 1 & 1 & 0.109 \\
\hline & & & & & $\Sigma=1.00$ \\
\hline
\end{tabular}




\subsection{Example 1}

Suppose an automation engineer $\mathrm{X}$ is engaged with PLC software development; the task belongs to the critical path and lasts 5 days. Assume that there is a requirement for a bid preparation by the same engineer because of his expertise, which requires 3 hours of engagement period, and the bid's difficulty is medium. Pairwise comparison matrixes for every criteria (Tables $2-5$ ) in such a situation are as follows:

The final rank given in Table 6 shows that the continuation of the primary task is strongly the best decision. The bid preparation has to be done from another engineer of the technical company or after the completion of the primary task from the engineer $\mathrm{X}$.

Tab. 2: Pairwise comparison matrix for criticality.

\begin{tabular}{llll}
\hline Criticality & Primary task & Secondary task & Priorities \\
\hline Primary task & 1 & 5 & 0.833 \\
Secondary task & $1 / 5$ & 1 & 0.166 \\
& & & $\sum=0.999$ \\
\hline
\end{tabular}

Tab. 3: Pairwise comparison matrix for complexity.

\begin{tabular}{llll}
\hline Complexity & Primary task & Secondary task & Priorities \\
\hline Primary task & 1 & 5 & 0.833 \\
Secondary task & $1 / 5$ & 1 & 0.166 \\
& & & $\Sigma=0.999$ \\
\hline
\end{tabular}

Tab. 4: Pairwise comparison matrix for duration.

\begin{tabular}{llll}
\hline Duration & Primary task & Secondary task & Priorities \\
\hline Primary task & 1 & $1 / 5$ & 0.166 \\
Secondary task & 5 & 1 & 0.833 \\
& & & $\Sigma=0.999$ \\
\hline
\end{tabular}

Tab. 5: Pairwise comparison matrix for appropriateness.

\begin{tabular}{llll}
\hline Appropriateness & Primary task & Secondary task & Priorities \\
\hline Primary task & 1 & 1 & 0.500 \\
Secondary task & 1 & 1 & 0.500 \\
& & & $\sum=1.000$ \\
\hline
\end{tabular}

\subsection{Example 2}

The automation engineer $\mathrm{X}$ is engaged with HMI software development; the task belongs to the critical path and lasts for 3 days. Suppose that there is an urgent requirement for a technical support to a customer from engineer $\mathrm{X}$ because this engineer made the whole software development and commissioning to his project. The support requires at least 4 hours of engagement period. Pairwise comparison matrixes for every criteria in such a situation (Tables 7-10) are as follows:

In this case, the final rank given in Table 11 shows that the primary task has to be paused and the engineer $\mathrm{X}$ must start giving technical support to the specific

Tab. 7: Pairwise comparison matrix for criticality.

\begin{tabular}{llll}
\hline Criticality & Primary task & Secondary task & Priorities \\
\hline Primary task & 1 & 1 & 0.500 \\
Secondary task & 1 & 1 & 0.500 \\
& & & $\Sigma=1.000$ \\
\hline
\end{tabular}

Tab. 8: Pairwise comparison matrix for complexity.

\begin{tabular}{llll}
\hline Complexity & Primary task & Secondary task & Priorities \\
\hline Primary task & 1 & $1 / 3$ & 0.250 \\
Secondary task & 3 & 1 & 0.750 \\
& & & $\Sigma=1.000$ \\
\hline
\end{tabular}

Tab. 9: Pairwise comparison matrix for duration.

\begin{tabular}{llll}
\hline Duration & Primary task & Secondary task & Priorities \\
\hline Primary task & 1 & 5 & 0.833 \\
Secondary task & $1 / 5$ & 1 & 0.166 \\
& & & $\Sigma=0.999$ \\
\hline
\end{tabular}

Tab. 10: Pairwise comparison matrix for appropriateness.

\begin{tabular}{llll}
\hline Appropriateness & Primary task & Secondary task & Priorities \\
\hline Primary task & 1 & $1 / 3$ & 0.250 \\
Secondary task & 3 & 1 & 0.750 \\
& & & $\sum=1.000$ \\
\hline
\end{tabular}

Tab. 6: Priority matrix for decision-making.

\begin{tabular}{llllll}
\hline & Criticality (0.485) & Complexity (0.297) & Duration (0.109) & Appropriateness (0.109) & Overall priority \\
\hline Primary task & 0.833 & 0.833 & 0.166 & 0.500 & 0.724 \\
Secondary task & 0.166 & 0.166 & 0.833 & 0.500 & 0.276 \\
\hline
\end{tabular}


customer. This will cause a time delay and, probably, an extra cost to the project.

\subsection{Analysis of subcriteria}

The abovementioned analysis could go one step further and investigate in more detail each of the aforementioned four criteria in the third level of the AHP hierarchy tree as shown in Figure 1. The authors chose to analyze in more detail the criterion "criticality", as according to Table 1 had the highest priority among the four criteria. The subcriteria for "criticality" that the four experts concluded were (Table 12): a) the company, i.e. regarding the importance of the task for the economic benefit of the company, b) the project, i.e. regarding the importance of the task for the on budget and on time execution of the project and c) the customer, i.e. regarding the importance of the task for the customer's satisfaction, which is crucial for the company (Tables 13-15).

If we apply the abovementioned analysis using the sub-criteria of "criticality" in our first example, only Table 2 changes, which is as follows (Table 16):

The analysis shows a slight increase in the overall priority of the primary task in relation to the secondary task. It could be argued that the incorporation of the subcriteria in our analysis offered a fine-tuning over the primary task.

\section{Conclusion and future research in civil engineering field}

Multitasking is a significant factor that affects human productivity and causes impacts on time and cost management of projects. Industrial automation

Tab. 11: Priority matrix for decision-making.

\begin{tabular}{llllll}
\hline & Criticality (0.485) & Complexity (0.297) & Duration (0.109) & Appropriateness (0.109) & Overall priority \\
\hline Primary task & 0.500 & 0.250 & 0.833 & 0.250 & 0.435 \\
Secondary task & 0.500 & 0.750 & 0.166 & 0.750 & 0.565 \\
\hline
\end{tabular}

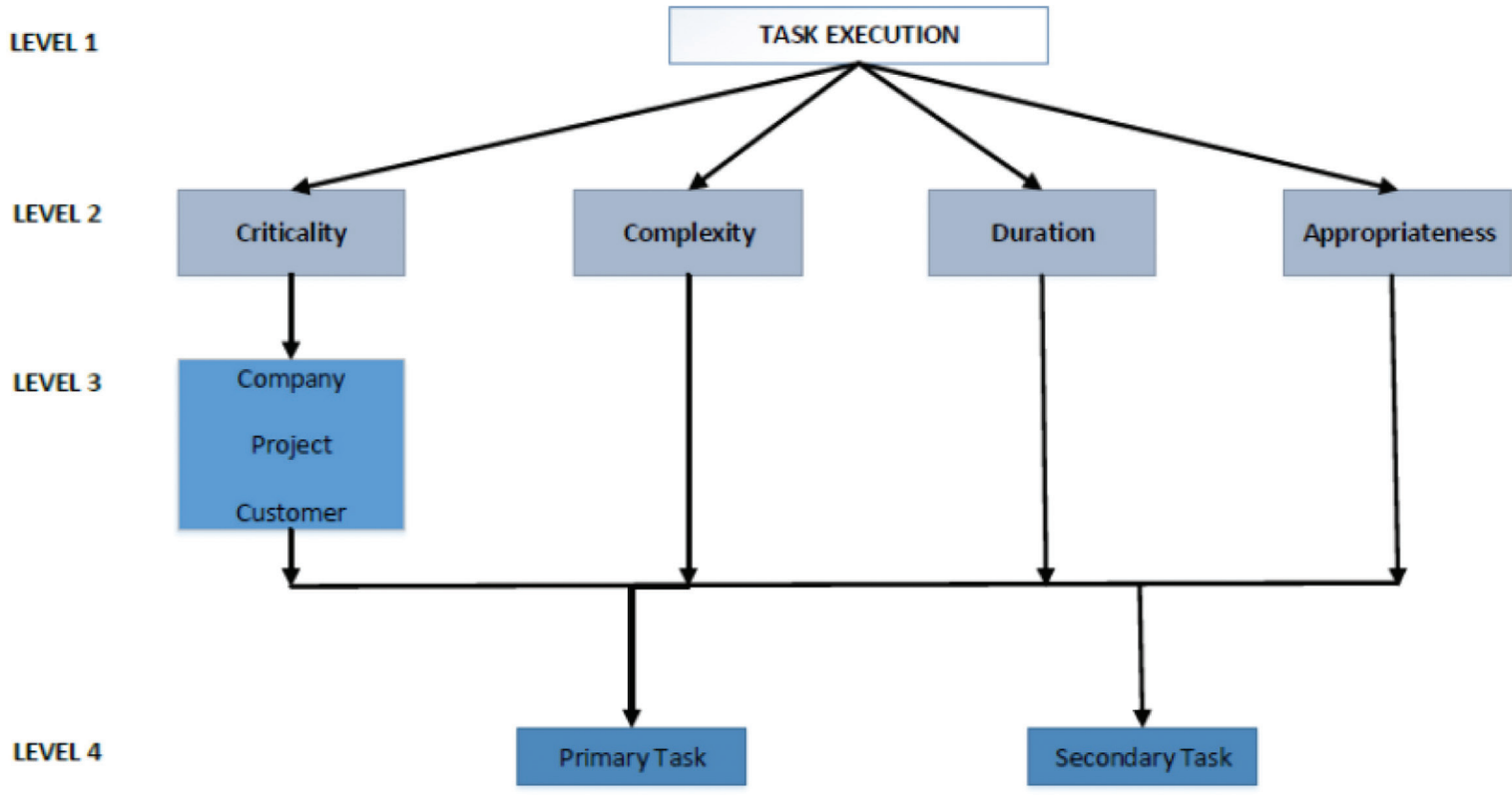

Fig. 1: AHP hierarchy tree for task selection with subcriteria. 
projects include tasks such as software development that strongly depends on human factors. This study presents the effects of multitasking within a project and depicts the consequences of some situations that a technical company has to face simultaneously in its everyday work environment. The conclusion is that multitasking impacts cannot be eliminated but have to be mitigated.

Tab. 12: Pairwise comparison matrix of the three subcriteria.

\begin{tabular}{lllll}
\hline & Company & Project & Customer & Priorities \\
\hline Company & 1 & 5 & 7 & 0.731 \\
Project & $1 / 5$ & 1 & 3 & 0.188 \\
Customer & $1 / 7$ & $1 / 3$ & 1 & 0.081 \\
& & & & $\Sigma=1.00$ \\
\hline
\end{tabular}

Tab. 13: Pairwise comparison matrix for criticality subcriteria: company.

\begin{tabular}{llll}
\hline Company & Primary task & Secondary task & Priorities \\
\hline Primary task & 1 & 5 & 0.833 \\
Secondary task & $1 / 5$ & 1 & 0.166 \\
& & & $\Sigma=0.999$ \\
\hline
\end{tabular}

Tab. 14: Pairwise comparison matrix for criticality subcriteria: project.

\begin{tabular}{llll}
\hline Project & Primary task & Secondary task & Priorities \\
\hline Primary task & 1 & 9 & 0.900 \\
Secondary task & $1 / 9$ & 1 & 0.100 \\
& & & $\Sigma=1.000$ \\
\hline
\end{tabular}

Tab. 15: Pairwise comparison matrix for criticality subcriteria: customer.

\begin{tabular}{llll}
\hline Customer & Primary task & Secondary task & Priorities \\
\hline Primary task & 1 & 5 & 0.833 \\
Secondary task & $1 / 5$ & 1 & $\begin{array}{l}0.166 \\
\end{array}$ \\
& & & $\sum=0.999$ \\
\hline
\end{tabular}

The AHP method is used as a tool to help the project manager to make the best decision regarding the resource allocation. The most significant factors that are taken into account for every decision are referred, and subjective priority vectors are given. The tool is used in two examples for different situations, and the best decision is calculated. Then, a further analysis is attempted; the most important criterion is analyzed in a list of subcriteria by the authors, and the results are presented.

It should be noted that the results of the tool do not necessarily provide the ideal decision for a project manager; this process analyzes parameters of the project that otherwise would have not been counted in the final decision. The importance of this tool is that it provides the project manager with the best choice in a quick and very user-friendly way.

The tool is developed in Microsoft Excel 2013 (the tool is available free from the corresponding author), and it can easily adopt changing criteria and priority vectors to adapt to specific type of projects. It may be used in different projects that strongly depend on human factors.

Civil engineering projects are highly depended on human factors. Decisions that should be made concerning the sharing of human resources in different activities out of schedule are very often required. These decisions mostly involve the unplanned assignment of workers or/ and superintendents to activities of the same project. These unforeseen events cause the disruption of the scheduled work. The criteria taken into account in decision-making of either to stop or not a work in progress in order to accommodate another activity are the same as for the industrial automation projects i.e. criticality, complexity, duration and suitability. Table 1 , referring to the criteria weights, may vary according to the project specifications, contract clauses and company's priorities. Future research in the construction field could identify additional criteria or/and subcriteria with different priority vectors.

Tab. 16: Priority matrix for decision-making.

\begin{tabular}{llllll}
\hline & Criticality (0.485) & Complexity (0.297) & Duration (0.109) & Appropriateness (0.109) & Overall priority \\
\hline Primary task & 0.846 & 0.833 & 0.166 & 0.500 & 0.730 \\
Secondary task & 0.154 & 0.166 & 0.833 & 0.500 & 0.270 \\
\hline
\end{tabular}




\section{References}

Adler, R. F., \& Benbunan-Fich, R. (2012). Juggling on a high wire: Multitasking effects on performance. International Journal of Human-Computer Studies, 70, pp. 156-168.

Alphonsus, E. R., \& Abdullah, M. O. (2016). A review on the applications of programmable logic controllers (PLCs). Renewable and Sustainable Energy Reviews 2016, 60, pp. 1185-1205.

APA. (2010). 6th edn. Available at http://www.apa.org/research/ action/multitask.aspx.

Bailey, B. P., Konstan, J. A., \& Carlis, J. V. (2001). The effects of interruptions on task performance, annoyance, and anxiety in the user interface. In: INTERACT 2001, NCP, Tokyo, Japan.

Buser, T., \& Peter, N. (2012). Multitasking. Experimental Economics, 15(4), pp. 1-15.

Czerwinski, M., Horvitz, E., \& Wilhite, S. (2004). A diary study of task switching and interruptions. In: Proceedings of CHI 2004, Vienna, Austria, April 24-29, pp. 175-182.

Gonzalez, V., Mark, G., \& Harris, J. (2005). No task left behind? Examining the nature of fragmented work. In: $\mathrm{CHI}$, Portland, OR, pp. 321-330.

Hardy, M., \& Gillan, D. J. (2012). Voluntary task switching patterns in everyday tasks of different motivational levels. In: Proceedings of the Human Factors and Ergonomics Society Annual Meeting, Boston, Vol. 56. SAGE Publications, Washington DC, pp. 2128-2132.

Ishizaka, A., \& Labib, A. (2011). Review of the main developments in the analytic hierarchy process. Expert Systems with Applications, 38, pp. 14336-14345.

Kenyon, S., \& Lyons, G. (2007). Introducing multitasking to the study of travel and ICT: Examining its extent and assessing its potential importance. Transportation Research Part A, 41, pp. 161-175.

Li, C., Ding, C., \& Shen, K. (2007). Quantifying the cost of context switch. In: Proceedings of the ACM Workshop Experimental Computer Science (ExpCS'07), San Diego, CA, USA. pp. 1-4, 2007.

Loh, K. K., \& Kanai, R. (2014). Higher media multi-tasking activity is associated with smaller gray-matter density in the anterior cingulate cortex. PLOS ONE, 9(9), p. e106698. doi: 10.1371/ journal.pone.0106698.
MCDM. http://www.mcdmsociety.org/content/mission-society on August, 2017.

Monk, C. A., Trafton, J. G., \& Boehm-Davis, D. A. (2008). The effect of interruption duration and demand on resuming suspended goals, Journal of Experimental Psychology: Applied, 14, pp. 299-213.

Novak, P., Sindelar, R., \& Mordinyi, R. (2014). Integration framework for simulations and SCADA systems. Simulation Modelling Practice and Theory, 47, pp. 121-140.

Ophir, E., Nass, C., \& Wagner, A. D. (2009). Cognitive control in media multitaskers. Proceedings of the National Academy of Sciences. Available at www.pnas.org/cgi/doi/10.1073/ pnas.0903620106

Patrick, F. S. (1999). Program management: Turning many projects into few priorities with TOC. In: Proceedings of the PMI-99 30th Annual Seminars and Symposiums. Project Management Institute, Newton Square, PA.

Saaty, T. (1980). The Analytic Hierarchy Process. McGraw-Hill, New York.

Saaty, T. L. (2008). Decision making with the analytic hierarchy process. International Journal of Services Sciences, 1(1), pp. 83-98.

Sanbonmatsu, D. M., Strayer, D. L., Medeiros-Ward, N., \& Watson, J. M. (2013). Who multi-tasks and why? Multi-tasking ability, perceived multi-tasking ability, impulsivity, and sensation seeking. PLoS One, 8(1), p. e54402.

Solingen, R., Berghout, E., \& Latum, F. (1998). Interrupts: Just a minute never is. IEEE Software, 15, pp. 97-103.

Vaidya, O. S., \& Kumar, S. (2006). Analytic hierarchy process: An overview of applications. European Journal of Operational Research, 169, pp. 1-29.

Watson, J. M., \& Strayer, D. L. (2010). Supertaskers: Profiles in extraordinary multi-tasking ability. Psychonomic Bulletin and Review, 17, pp. 479-485

Witt, B. I., \& Lambert, W. (1965). Systems Reference Library IBM Operating System/360 Concepts and Facilities. IBM Systems Reference Library, 1-91.

Xu, D. L., \& Yang, J. B. (2001). Introduction to multi-criteria decision making and the evidential reasoning approach. In: Working Paper Series, Paper No. 0106, Manchester School of Management, University of Manchester Institute and Technology, ISBN: 186115111 X, May. 